\title{
Conhecimento de estudantes de Odontologia sobre Suporte Básico de Vida em
}

\author{
Adultos \\ Dentistry student's knowledge of Basic Adult Life Support \\ Conocimientos de estudiantes de Odontología sobre Soporte Vital Básico para Adultos
}

Recebido: 14/12/2021 | Revisado: 22/12/2021 | Aceito: 07/01/2022 | Publicado: 10/01/2022

Juliana Damasceno da Silva

ORCID: https://orcid.org/0000-0002-2992-3656

Centro Universitário do Estado do Pará, Brasil

E-mail: juliana_ddamasceno@ hotmail.com

Viktória Karla Monteiro Cardoso

ORCID: https://orcid.org/0000-0002-3595-4758

Centro Universitário do Estado do Pará, Brasil

E-mail: viktoriamonteiro@yahoo.com

Aluísio Ferreira Celestino Júnior

ORCID: https://orcid.org/0000-0002-1472-5155

Centro Universitário do Estado do Pará, Brasil E-mail: aluisio.junior@prof.cesupa.br

Jéssica Mendes Damasceno Lira

ORCID: https://orcid.org/0000-0001-5076-4613 Escola Superior da Amazônia, Brasil E-mail: jessica_jmd@hotmail.com

Jorge Sá Elias Nogueira

ORCID: https://orcid.org/0000-0001-7493-6475

Centro Universitário do Estado do Pará, Brasil E-mail: jorge.nogueira@prof.cesupa.br

Oscar Faciola Pessoa

ORCID: https://orcid.org/0000-0002-4386-4613

Centro Universitário do Estado do Pará, Brasil

E-mail: ofpessoa@cesupa.br

\begin{abstract}
Resumo
$\mathrm{O}$ alto índice de mortalidade nas Paradas Cardiorrespiratórias (PCR) dá ênfase às medidas emergenciais para reduzir esses índices como as manobras de Suporte Básico de Vida (SBV). O SBV constitui o atendimento inicial, extrahospitalar, prestado à vítima de PCR e que representam conduta de grande impacto na redução de óbitos quando adequadamente implementadas. É imprescindível que haja pessoas capacitadas para realizar essas manobras que podem ocorrer em momento e ambientes diversos, incluindo durante o atendimento em saúde bucal. Este estudo teve por objetivo avaliar o conhecimento de estudantes do último semestre do curso de odontologia de duas instituições de ensino sobre SBV em Adultos. A pesquisa foi realizada através de um questionário estruturado contendo dez questões sobre o conhecimento e conduta adequadas em casos de PCR. Verificou-se que, em sua maioria, os estudantes apresentaram resultados aceitáveis, porém uma parcela ainda importante desconhece as manobras e condutas corretas realizadas no SBV e que tal parcela de estudantes respondeu não se sentir preparada para lidar com tal situação com segurança.
\end{abstract}

Palavras-chave: Reanimação cardiopulmonar; Sinais vitais; Parada cardíaca.

\begin{abstract}
The high mortality rate in cardiopulmonary arrests (CPA) emphasizes emergency measures to reduce these rates, such as Basic Life Support (BLS) maneuvers. The BLS constitutes the initial out-of-hospital care provided to the victim of CPA, which represents a conduct with a great impact on the reduction of deaths when properly implemented. It is essential that there are people trained to perform these maneuvers that can occur at different times and environments, including during oral health care. This study aimed to evaluate the knowledge of students in the last semester of the dentistry course at two educational institutions about BLS in Adults. The research was carried out through a structured questionnaire containing ten questions about knowledge and proper conduct in cases of CPA. It was found that, for the most part, students had acceptable results, but a still significant portion is unaware of the correct maneuvers and behaviors performed in the SBV and that such portion of students responded that they did not feel prepared to handle such a situation safely.
\end{abstract}

Keywords: Cardiopulmonary resuscitation; Vital signs; Heart arrest. 


\begin{abstract}
Resumen
La alta tasa de mortalidad en las paradas cardiopulmonares (PCR) enfatiza las medidas de emergencia para reducir estas tasas, como las maniobras de Soporte Vital Básico (SVB). El SVB constituye la atención extrahospitalaria inicial brindada a la víctima de CPA, lo que representa una conducta de gran impacto en la reducción de muertes cuando se implementa adecuadamente. Es fundamental que haya personas capacitadas para realizar estas maniobras que pueden ocurrir en diferentes momentos y ambientes, incluso durante el cuidado de la salud bucal. Este estudio tuvo como objetivo evaluar los conocimientos de los estudiantes del último semestre del curso de Odontología de dos instituciones educativas sobre SVB en Adultos. La investigación se llevó a cabo a través de un cuestionario estructurado que contiene diez preguntas sobre el conocimiento y la conducta adecuada en los casos de PCR. Se encontró que, en su mayor parte, los estudiantes obtuvieron resultados aceptables, pero una parte aún significativa desconoce las maniobras y comportamientos correctos realizados en el SVB y esa parte de los estudiantes respondió que no se sentían preparados para manejar tal situación. sin peligro.
\end{abstract}

Palabras clave: Reanimación cardiopulmonar; Signos vitales; Paro cardíaco.

\title{
1. Introdução
}

As doenças cardiovasculares estão entre as principais causas de morte no mundo. Anualmente, mais de 800 mil eventos de PCR (parada cardiorrespiratória) são registrados na Europa e nos Estados Unidos. No Brasil, os dados sobre mortalidade são imprecisos, entretanto, as doenças cardiovasculares continuam sendo a principal causa de mortalidade. É importante ressaltar que, a cada minuto que uma vítima em PCR não recebe Ressuscitação Cardiopulmonar (RCP), ela perde de 7 a 10\% de chance de sobreviver; é o que afirma a atualização da Diretriz de Ressuscitação Cardiopulmonar e Cuidados Cardiovasculares de Emergência da Sociedade Brasileira de Cardiologia (2019).

Portanto, as ações realizadas durante os minutos iniciais de atendimento a uma emergência são críticas em relação à sobrevivência da vítima. O SBV é definido como uma sequência primária de ações para salvar vidas. Por mais adequado e eficiente que seja um Suporte Avançado, se as ações de suporte básico não forem realizadas de maneira adequadas, será extremamente baixa a possibilidade de sobrevivência de uma vítima de PCR (Silva et al., 2020), sendo, portanto, desafiadora como afirmam Meng et al. (2021), mas essencial atingir uma faixa ideal de compressão torácicas de maneira eficiente e com qualidade, pois numerosas evidências clínicas já provaram que a compressão rasa, liberação incompleta da compressão e a taxa de compressão inadequada podem resultar em perfusão coronariana pobre e baixo débito cardíaco durante a RCP.

Por estas razões, a estratégia de capacitar leigos e principalmente os diversos profissionais da saúde, tem grande relevância, pois grande parte desses eventos patológicos ocorre em ambiente extra-hospitalar, o que requer rapidez e razoável perícia no socorro à vítima, sendo exigida habilidade do socorrista e a aplicação da sequência correta da RCP para que haja a preservação da vida até a chegada da unidade de pronto atendimento (Dixe et al., 2016).

O treinamento em suporte básico de vida é uma realidade nas escolas da maior parte dos países da Europa. Infelizmente, no Brasil esse quadro é bem diferente. Em grande parte das faculdades de odontologia o tema "primeiros socorros" é pouco abordado (Clotet et al., 2011). Andrade et al. (2013) são categóricos ao afirmarem que O SBV envolve o reconhecimento imediato de um quadro de parada cardíaca, o acionamento precoce do serviço médico de urgência como o SAMU, o início imediato das manobras de RCP e a rápida utilização de um desfibrilador externo automático (DEA).

Conforme recomendado nos destaques das Diretrizes de 2015 da American Heart Association atualizada em 2019 (AHA, 2019) com ênfase no SBV aplicado por profissionais da saúde, estes devem, primeiramente, verificar a segurança do local para os socorristas e a vítima. Em seguida, pedir ajuda nas proximidades ao encontrarem uma vítima que não responde. Porém é bastante prático o profissional de saúde continuar a avaliar a respiração e o pulso simultaneamente antes de acionar o serviço médico de emergência. É aconselhado, se estiver sozinho sem acesso a um telefone celular, deixar a vítima e acionar o serviço médico de emergência e idealmente obter um DEA, antes de iniciar a RCP. Do contrário, deve-se pedir que alguém acione o serviço de urgência e logo se inicia a RCP, usando o DEA assim que ele estiver disponível. 
A verificação da pulsação pelos profissionais da saúde deve ser limitada a não mais que 10 segundos para evitar atrasos no início das compressões torácicas. Idealmente, a verificação do pulso é realizada simultaneamente com a verificação de ausência de respiração ou respiração ofegante, para minimizar atraso na detecção da parada cardíaca e o início da RCP (Bobrow et al., 2015).

Em vítimas adultas de PCR, o correto é que os socorristas apliquem com as duas mãos sobre a metade inferior do esterno, compressões torácicas a uma frequência de 100/120 min., até uma profundidade de, pelo menos $5 \mathrm{~cm}$ para um adulto médio, evitando excesso na profundidade das compressões torácicas (superiores a $6 \mathrm{~cm}$ ). Os socorristas devem evitar apoiar-se sobre o tórax entre as compressões, para permitir o retorno total da parede do tórax (AHA, 2019).

Uma vez que as compressões torácicas foram iniciadas, um socorrista treinado oferece ventilações de resgate boca-aboca ou máscara de bolsa para fornecer oxigenação e ventilação, aplicadas na relação de 30 compressões para cada 2 ventilações. O socorrista deve continuar com a RCP até que um DEA esteja disponível para uso ou os prestadores de serviços de emergência prestem cuidados à vítima (AHA, 2015).

Estas informações dão ênfase para a importância de medidas educativas que contribuam para a assistência de RCP. Tais medidas dizem respeito também a treinamento de estudantes na área da saúde, como os estudantes de odontologia (Owojuyigbe et al., 2015), pois na odontologia os pacientes atendidos são, eventualmente, submetidos ao estresse gerado por fobia e a administração de anestésicos locais com vasoconstritores; fatores estes que podem interferir no sistema cardiovascular e consequentemente concorrer para uma PCR (Bravin et al., 2018). Os cirurgiões-dentistas (CDs), portanto, devem estar habilitados para execução adequada de tais procedimentos, pois no ambiente de cuidado ao paciente ou mesmo fora dele, poderão se deparar com casos de parada cardiorrespiratória e poderão atuar de maneira eficaz. Para melhorar a taxa de sobrevivência diante de parada cardíaca, entretanto, há necessidade imperiosa de que sejam adequadamente treinados (Owojuyigbe et al., 2015).

O objetivo deste estudo foi avaliar o conhecimento de estudantes do último semestre do curso de odontologia de Belém-PA acerca de suas habilidades em relação ao SBV em Adultos que compõem o conjunto de medidas emergenciais necessárias diante de uma PCR.

\section{Metodologia}

A proposta de estudo consistiu em uma pesquisa de campo de natureza quantitativa de recorte transversal com abordagem descritivo-exploratória de caráter transversal (Estrela, 2018). A coleta de dados foi realizada em duas faculdades de odontologia localizadas na cidade de Belém-PA, sendo elas: Centro Universitário do Pará (CESUPA) e Universidade Federal do Pará (UFPA).

Foram avaliados estudantes do último semestre do curso de odontologia de duas faculdades de Belém-Pará. Esta escolha se deve ao fato de que alunos considerados concluintes já devem ter competências e habilidades assimiladas frente ao objeto de estudo. Apenas três faculdades de odontologia na cidade de Belém tinham estudantes concluintes durante a coleta de dados. A terceira instituição não autorizou a participação de seus estudantes na pesquisa.

Os dados foram coletados através de um questionário extraído e adaptado pelos autores a partir de estudos de Brum et al. (2016) e de Aquino et al. (2010).

Este questionário consta de dez perguntas relacionadas à informação e importância do SBV e a conduta adequada a ser realizada nos casos de PCR. A coleta de dados foi realizada após aprovação do protocolo de pesquisa pelo Comitê de Ética e Pesquisa (CEP) das duas instituições envolvidas sob o protocolo nº 3.561.351. 


\section{Resultados}

Após a aplicação dos critérios de elegibilidade da pesquisa, chegou-se a um total de 54 estudantes participantes da pesquisa.

Na primeira pergunta do questionário, $96 \%$ dos alunos responderam que já ouviram falar em SBV enquanto 3\% dos alunos nunca tinham ouvido falar.

Quando perguntado aos alunos se já receberam algum tipo de instrução em SBV, 79\% dos alunos responderam que já receberam. Desses $79 \%$ de estudantes, $61 \%$ não se sentiam preparados para efetuar as manobras em uma situação de emergência enquanto 38\% sentiam-se preparados; $20 \%$ dos alunos responderam que não receberam nenhum tipo de instrução em SBV. Apenas um aluno não respondeu esta pergunta.

Quanto à situação em que local/ocasião receberam instrução sobre SBV, 15\% dos alunos responderam que receberam em um curso sobre o tema; $53 \%$ em aulas na faculdade; $15 \%$ marcaram outros e $15 \%$ afirmaram nunca terem recebido instrução.

Quanto ao diagnóstico de parada cardiorrespiratória, sendo considerada a resposta correta "presença de pulso e respiração", $73 \%$ dos alunos responderam corretamente, enquanto $26 \%$ assinalaram outras opções.

Quanto a questão de como se verifica se a vítima está respirando e considerado como resposta correta "através de movimentos respiratórios e através da aproximação até a boca ou nariz da vítima", 57\% dos alunos responderam corretamente enquanto $42 \%$ marcaram outras opções.

Quanto ao local correto das compressões $66,6 \%$ responderam corretamente enquanto $44,4 \%$ assinalaram outras alternativas.

Ao perguntar sobre qual número de telefone ligar para pedir ajuda, 81\% dos alunos marcaram "192" (SAMU), enquanto $1 \%$ marcou "911"; $7 \%$ marcaram "193" e 9\% marcaram "190".

Referente a relação compressão/ventilação diante de uma vítima de PCR 51\% dos estudantes das duas instituições responderam corretamente.

Em relação a sequência correta de procedimentos diante de uma PCR, apenas 37\% dos estudantes a responderam corretamente.

\section{Discussão}

Embora parte considerável dos estudantes tenha respondido corretamente sobre as manobras de SBV, um número importante de estudantes mostrou desconhecimento de como agir em tais manobras. Os dados demonstram ainda que muitos destes estudantes receberam informações na graduação sobre o objeto deste estudo, porém com variável grau de fixação das habilidades individuais sobre as condutas. Este resultado vai ao encontro do estudo de Manton et al. (2021) que concluíram que estudantes que tiveram um currículo modificado, baseados em simulação, comparados ao currículo padrão, composto apenas por palestras, tiveram melhor desempenho em gerenciar emergências médicas.

Segundo Victorelli et al. (2013), o treinamento em BVS é imprescindível ao profissional, porém a maior preocupação dos profissionais de odontologia ainda é com a atualização e capacitação técnica que em geral fica muito concentrada no sistema estomatognático. Como qualquer outro profissional de saúde, os CDs devem estar atento a atualização permanente buscando conhecimento com relação às emergências médicas, incluindo dentre elas as manobras de SBV e de RCP, pois, segundo Herrera et al. (2021), as emergências médicas durante a atenção odontológica são eventos que podem pôr em perigo a vida do paciente.

Quando abordado sobre o treinamento acerca de SBV, o presente estudo mostra resultados positivos quanto aos estudantes que já receberam instruções, ou seja, 79\% afirmaram já ter recebido. Em estudo similar realizado por Pereira $e t$ al. 
(2019), 54\% dos alunos de odontologia afirmaram não possuir treinamento em SBV, percentual menor dos resultados aqui apresentados. Por esse motivo Solanki et al. (2021), são enfáticos ao afirmar a necessidade de mais treinamento durante a formação profissional.

Gazal et al. (2021), após avaliarem o nível de conhecimento relacionado a emergências médicas entre estudantes do último ano de odontologia na Arábia Saudita sobre o gerenciamento de crises de emergência médica em odontologia, concluíram que há um aumentado gradual na capacidade com o número de anos de experiência, porém, a maioria dos participantes reconhece a necessidade de mais treinamento.

Apesar de 79\% dos estudantes afirmarem ter recebido instruções, $61 \%$ desse grupo não se sentiam preparados para efetuar as manobras em uma emergência. Em estudo realizado por Dutra e Silva (2021) verificou-se que a maioria dos estudantes de odontologia não haviam recebido qualquer treinamento em SBV (87,3\%). Dos estudantes avaliados neste estudo, $98,4 \%$ relataram ter medo de realizar alguma conduta incorreta durante as manobras de SBV.

Santos e Rumel (2006) citam que, embora as manobras de RCP sejam apresentadas na graduação, muitos profissionais não se julgam capazes de executar o procedimento de forma correta. Trata-se de um procedimento relativamente simples, porém que exige muita rapidez e conhecimento em toda sua sequência.

Quando abordado sobre o local de instrução, 53\% dos alunos relataram ter recebido conhecimento sobre o tema na faculdade. Enquanto Caputo et al. 2010, em seu estudo afirmam que a principal fonte onde os participantes receberam instrução em SBV foram os cursos extracurriculares com $40 \%$ das afirmações, distinto dos resultados aqui apresentados.

Neste estudo verificou-se que $51 \%$ dos alunos responderam corretamente sobre a relação compressão/ventilação torácicas. Estes achados corroboram com os de Rosa e Colenci (2009), onde 53,3\% da equipe de enfermagem referiram conhecimento adequado da razão compressão/ventilação atualmente preconizada. Entretanto, o estudo de Monteiro et al. (2018), afirma que $88,7 \%$ não conhecem o número de compressões que devem ser feitas no tórax. E apenas $14,4 \%$ sabiam a relação compressão/ventilação.

Quanto ao diagnóstico de parada cardiorrespiratória a resposta correta "ausência de pulso e respiração", 73\% dos alunos responderam corretamente. Semelhante aos achados de Fabris et al. (2015), onde cerca de 52\% foram capazes de reconhecer alguém com necessidade de RCP.

Segundo Kumar et al. (2014) a avaliação do pulso é que vai determinar se o paciente está apresentando uma PCR sendo assim, se os CDs não souberem avaliar corretamente o pulso do seu paciente, não poderá diagnosticar a ocorrência de uma emergência, muito menos suprir com as necessidades de SBV até a chegada do socorro.

Neste estudo verificou-se que $66,60 \%$ dos alunos responderam corretamente o local do corpo da vítima que se realiza a compressão torácica. Já o estudo realizado por Pergola e Araújo (2009), mostra que apenas 8,8\% responderam corretamente o local da compressão, enquanto $63,4 \%$ responderam parcialmente correto.

Quando perguntado como se verifica se a vítima está respirando, 57\% dos alunos responderam corretamente, através de "movimentos respiratórios e aproximação até a boca ou nariz da vítima". Enquanto no estudo de Pergola e Araújo (2009) em leigos, $75,8 \%$ da amostra respondeu corretamente. O fato de $42 \%$ dos alunos dessa pesquisa responderem incorretamente é preocupante, pois pode atrasar o socorro à vítima.

Monazzi et al. (2001), afirmaram que é de grande importância que os CDs tenham aptidão para realizar manobras básicas quando se depararem com uma situação de emergência para assegurar a saúde do paciente até que o mesmo receba um atendimento especializado.

De acordo com American Heart Association em suas diretrizes de 2015 (AHA, 2015), o socorrista ao presenciar uma situação de emergência, deve verificar a segurança do local; reconhecer a PCR; pedir ajuda e aplicar a desfibrilação. No presente estudo apenas $37 \%$ responderam a sequência correta a ser realizada, observando-se que $63 \%$ dos estudantes 
apresentam falta de conhecimento ao lidarem com uma situação emergencial. Dados semelhantes foram encontrados no estudo de Fabris et al. (2015), onde observou-se que boa parte dos profissionais não possuem conhecimento adequado para atuar de maneira correta no início de uma emergência.

Emergências médicas mesmo não sendo comuns, podem ocorrer em ambiente odontológico acometendo qualquer indivíduo antes, durante ou após uma intervenção. Dessa forma é necessário não só o conhecimento técnico e cientifico sobre tais ocorrências como também um perfeito domínio por parte do profissional do atendimento necessário a fim de assegurar a manutenção da vida do paciente (Caputo et al., 2010).

Observa-se que este trabalho apresentou resultados aceitáveis na maioria das questões analisadas, mostrando o conhecimento da maioria dos estudantes avaliados sobre o tema, porém não representa unanimidade, o presente trabalho também mostra que uma parcela importante dos alunos ainda desconhece as manobras e condutas corretas realizadas no SBV em adultos.

Apesar de grande parte dos estudantes afirmar ter participado de treinamento em SBV a maioria não se sente preparado para lidar com tal situação. O fato de $15 \%$ afirmarem que nunca receberam instrução, ressalta a importância do investimento e estímulo durante a graduação, assim como exercícios práticos como atividades de simulação realística a fim de se sentirem mais seguros para a execução de tais manobras emergenciais (Gontijo et al, 2021).

Os estudantes desta pesquisa demostraram pouco conhecimento em relação à sequência correta das manobras de emergência diante de uma PCR, dado muito preocupante. E que não estão inteiramente preparados para agir corretamente nesses casos. Cabe ressaltar que, os treinamentos voltados para a simulação prática de emergências são fundamentais na formação da área da saúde, devendo-se utilizar recursos pedagógicos que favoreçam o engajamento dos estudantes e que os estimule a buscarem atualização constante nos conhecimentos desta área (Maigret et al., 2021).

Ratifica-se, portanto, a necessidade de mais estudos envolvendo o conhecimento de estudantes de odontologia em PCR e SBV assim como a inclusão definitiva nos currículos, programas teóricos e práticos envolvendo tão relevantes assuntos.

\section{Conclusão}

Após análise dos resultados, concluímos que os estudantes envolvidos nesta pesquisa demostraram pouco conhecimento em relação à sequência correta da PCR, não se sentem seguros para realização da manobra de SBV o que denota a necessidade de inserção de aulas práticas em manequins para melhor fixação dos aprendizados.

Pesquisas semelhantes devem ser realizadas com um universo maior de pesquisados bem como em outras instituições de ensino da graduação. Diante dos resultados apresentados neste estudo, poderá ser considerada a realização de estudos que possam aferir o conhecimento/conduta de estudantes antes e após a realização de um treinamento sobre suporte básico de vida.

\section{Referências}

American Heart Association: CPR and ACE-2015 Guidelines UpdateAvailable: <https://eccguidelines.heart.org/wpcontent/uploads/2015/10/2015-AHAGuidelines-Highlights-English.pdf>.

American Heart Association: CPR and ACE-2015 Guidelines UpdateAvailable: <https://eccguidelines.heart.org/wpcontent/uploads/2019/12/2019-AHAGuidelines-Highlights-English.pdf>.

Andrade, E. D., Motta R. H. L., Ramacciato J. C., Ranali J. C., \& Victorelli G. (2013). Basic Life Support and Cardiopulmonary Resuscitation in Adults: Current Concepts and New Recommendations. Associação Paulista Magazine Dental Surgeon, 67.

Aquino, V. S., Carneiro, S. R., Silva, M. S. V., Neves, L. M. T. \& Reis, H. J. L. (2010). Conhecimento de fisioterapeutas sobre a atuação em suporte básico de vida. Fisioterapia e Pesquisa.17(1), 69-74. 
Bobrow, B. J., Brennan, E. E., Gazmuri, R. J., Goldberger, Z. D., Hazinski, M. F., Hemphill, R. et al (2017). Part 5: Adult Basic Life Support and Cardiopulmonary Resuscitation Quality. American Heart Association, Web-based Integrated Guidelines for Cardiopulmonary Resuscitation and Emergency Cardiovascular Care.

Bravin, R., Sobrinho, A., \& Seixas, M. (2018). The importance of Basic Life Support in Dentistry. Journal Of The Faculty Of Dentistry, 23(3).

Brum, I. V., Neto, J. A. C., Pereira, D. R., Santos, L. G., Moraes, S. L., \& Ferreira, R. E. (2016). Knowledge and Interest in Basic Life Support among Lay People. International Journal of Cardiovascular Sciences, School of Medicine, Federal University of Juiz de Fora, Juiz de Fora, MG - Brazil, 29 (6), $443-452$.

Caputo, I. G. C., Bazzo, G. J., Silva, R. H. A., Júnior, E. D. (2010). Lives at Risk: Medical Emergencies in the Dental Office. Rev. Cir. Traumatol BucoMaxilo-Fac, Camaragibe.10(3), 51-58.

Clotet, D., Griza, G. L., Fleig, C. N., Conci, R. A., Sinegalia, A. C. (2011). Are academics and dental professionals prepared to save lives? RFO UPF.16(1).

Dixe, M. A. C. R., Gomes, J. C. R. (2015). Knowledge of the Portuguese population about basic life support and willingness to undertake training. Journal of the School of Nursing. 640-649.

Dutra, N. G. S., \& Silva, M. A. S. (2021). Emergências Médicas: Estudantes de odontologia estão preparados para atuar nesse tipo de situação? Revista de Saúde, 12(3), 03-10.

Estrela, C. (2018). Metodologia Científica: Ciência, Ensino, Pesquisa. Editora Artes Médicas.

Fabris, V., Junqueira, J. L. C., Silva, M. B. F., Oliveira, F. M. G. R., Lucas, A. (2015). Evaluation of dentists' knowledge about basic life support in the face of medical emergencies in dentistry. J Oral Invest, 4 (2), 50-56.

Gazal, G., Aljohani, H., Al-Samadani, K. H., Nassani, M. Z. (2021). Measuring the Level of Medical-Emergency-Related Knowledge among Senior Dental Students and Clinical Trainers. Int. J. Environ. Res. Public Health, 18, 68-89.

Herrera, I. A. R., Navarro, D. M., Soto, A. R. (2021). Urgencias médicas durante la experiencia profesional de estomatólogos en La Habana. Medical emergencies in the professional practice of Havana dentists. Rev Cubana Estomatol, 58(2),32-71.

Kumar, G., Joseph, N., Babu, Y., Nelliyanil, M., Bhaskaran, U. (2014). Knowledge of first aid skills among students os a medical college in mangalore city of south índia. Annals of Medical and Health Sciences Research, 4(2),16-26.

Maigret, S. B., Minharro, M. C. O., \& Alencar, R. A. (2021). Estratégias de ensino da simulação do Suporte Básico de Vida em Enfermagem: Uma revisão integrativa. Research, Society and Development, 10(9).

Manton, J. W., Kennedy, K. S., Lipps, J. A., Pfeil, S. A., Cornelius, B. W (2021). Medical Emergency Management in the Dental Office (MEMDO): A Pilot Study Assessing a Simulation-Based Training Curriculum for Dentists. Anesth Prog, 68 (2), 76-84.

Meng, X., You, J., Dai, L., Yin, X., Xu, J., Wang, J. (2021). Efficacy of a Simplified Feedback Trainer for High-Quality Chest Compression Training: A Randomized Controlled Simulation Study. Front Public Health.

Monnazzi, M. S., Prata, D. M., Vieira, E. H., Gabrielli, M. A. C., Carlos, E. (2001). Emergencies and Medical Urgencies. How to proceed? RGO, 49(1),7-11.

Monteiro, M. J. F. S. P., Pereira, M. C. A. R. S., Carvalho, R. M. B. C., Carril, É. S. B., Carril, M. F. B., Rodrigues, V. M. C. P. (2018). Training of workers in basic life support. Care Rev, 9 (2), 211-726.

Owojuyigbe, A., Adenekan, A., Faponle, A. F., Olateju, S. O. (2015). Impact of basic life support training on the knowledge of basic life support in a group of Nigerian Dental Students. Nigerian Postgraduate Medical Journal, Nígeria, 22(3).

Pereira, B. S. F., Rodrigues, W. J. P. R., Silveira, R. G. (2019). Knowledge Analysis of UNIFESO Dentistry students about ethical and legal aspects of medical emergencies in Dentistry. JOPIC MAGAZINE, 2 (4).

Pergola, A. M., Araujo, I. E. M. (2009). The layman and the basic life support. Rev. Esc, sick USP, 43(2).

Rosa, D., \& Colenci, R. (2009). Knowledge of a nursing staff of a hospital about cardiopulmonary arrest. In: VII Nursing Week 2009.Anais, São Manuel: Marechal Rondon College.

Santos, J. C., \& Rumel, D. M. (2006). Emergency in dental practice in Santa Catarina State: occurrence, equipment and drugs, knowledge and training of dental surgeons. Science and public health, 11(01), 183-190.

Silva, B. K. M., Tassara, K. R., Ansaloni, L.V. S., Moraes, P. H. A., Oliveira, R. A. de, \& Matias, P. R. S. (2020). O conhecimento acerca do suporte básico de vida: uma revisão integrativa. Braz. J. of Develop., 6(9),72021-72039.

Sociedade Brasileira de Cardiologia (2019). Atualização da Diretriz de Ressuscitação Cardiopulmonar e Cuidados Cardiovasculares de Emergência da Sociedade Brasileira de Cardiologia. 
Research, Society and Development, v. 11, n. 1, e41211124738, 2022

(CC BY 4.0) | ISSN 2525-3409 | DOI: http://dx.doi.org/10.33448/rsd-v11i4.24738

Solanki, C., Geisinger, M. L., Luepke, P. G., Al-Bitar, K., Palomo, L., Lee, W., Blanchard, S., Shin, D., Gerardo, M., Eckert, G. J., \& John, V. (2021). Assessing readiness to manage medical emergencies among dental students at four dental schools. J Dent Educ, 85 (9), 1462-1470.

Victorelli, G., Ramacciato, J. C., Andrade, E. D., Ranali, J., \& Motta, R. H. L. (2013). Basic Life Support and Cardiopulmonary Resuscitation in Adults: Current Concepts and New Recommendations. Journal of the Paulista Association of Dental Surgeons, 67(2), 124-128. 